Article

\title{
LEED-CI V3 and V4 Silver and Gold Projects in China and the U.S.
}

\author{
Svetlana PushkariD \\ Department of Civil Engineering, Ariel University, Ariel 40700, Israel; svetlanap@ariel.ac.il
}

Received: 23 May 2020; Accepted: 28 June 2020; Published: 29 June 2020

\begin{abstract}
Leadership in Energy and Environmental Design Commercial Interiors (LEED-CI) versions 4 (v4) and 3 (v3) Silver and Gold projects have been widely used in both the U.S. and China. This study aimed to compare the LEED-CI-Silver and LEED-CI-Gold v3 and v4 in China and the U.S. The design of the study comprised two stages: (1) to identify all LEED-CIv4 projects in China and the U.S. at the Silver and Gold levels for 2014-2019; and (2) to collect the same number of LEED-CIv3 projects for each certification level from the same cities of China and from the same states of the U.S. at the same times, if possible. Cliff's $\delta$ or the log odds ratio effect size was used to evaluate the difference between the achieved and the possible points, and the difference between the Silver and Gold projects in China and the U.S. The results show that, in the Silver-to-Gold transition, in China, the water-energy-site-human health saving strategy was used, while in the U.S., only the water-energy saving strategy was used.
\end{abstract}

Keywords: LEED-CI v4 v3; China; the U.S.; LEED Silver-to-Gold certification; effect size

\section{Introduction}

Currently, green building certification is a common approach to building in a sustainable way. Due to the differing existing environmental, political, economic, social, and technological contexts of different countries, it is accepted that appropriate green rating systems can be developed for specific countries. However, some country-specific systems have also received much attention in foreign countries; the most prominent example of such a foreign-accepted system is Leadership in Energy and Environmental Design (LEED). This system was initially developed (in 1998) in the U.S. by the U.S. Green Building Council (USGBC), a non-profit coalition of the building industry [1].

It should be noted that LEED was built as a measure of sustainability. According to [2], sustainability should encompass environmental sustainability, economic sustainability, and social sustainability. In this respect, Castellano et al. [3] analyzed LEED sustainability aspects and confirmed that $83 \%$ of the credits are related to environmental sustainability, $16 \%$ of the credits deal with social sustainability, and $1 \%$ of the credits refer to economic sustainability. Similar results were presented by Illankoon et al. [4], who concluded that LEED devotes $74.59 \%, 18.03 \%, 0.82 \%$, and $6.56 \%$ of credits to environmental sustainability, social sustainability, economic sustainability, and others, respectively. However, LEED is still named as the most popular green rating system in the world [1].

According to Ade and Rehm [1], the first version of LEED (LEEDv1) was designed for new building and included a simple list of sixteen credits (for example, Indoor Air Quality with 85\% air filtration, Temperature according to ASHRAE 55-1992, Energy Conservation according to ASHRAE 90.1-1989), while four of the credits (for example, Waste Disposal and Smoking Ban) were mandatory. Each of the credits was awarded one point. Next, LEEDv2, which was launched in 2000, divided credits into five categories (Land, Water, Energy, Materials, and Indoor Environmental Quality). LEEDv2 was a turning point to further expand the LEED system to different building types: LEED-NCv2.2, 
LEED-C\&S, LEED-EB, LEED-CI, and Homes, for newly constructed buildings, core and shell buildings, existing buildings, commercial interiors, and homes, respectively, were introduced in 2004 and 2005.

LEED-NCv2.2 consisted of six categories [1]—Sustainable Sites (SS, 14 points), Water Efficiency (WE, five points), Energy and Atmosphere (EA, 17 points), Materials and Resources (MR, 13 points), Indoor Environmental Quality (EQ, 15 points), and Innovation and Design Process (IN, 5 points)—summing to 69 points in total. Four certification levels-Certified (26-32 points), Silver (33-38 points), Gold (39-51 points), and Platinum (52-69 points) -were introduced. However, the credits were still weighted equally (one point to each credit).

The next version, LEED-NCv3, was introduced in 2009 [1]. This version included seven categories: SS (26 points), WE (10 points), EA (35 points), MR (14 points), EQ (15 points), IN (6 points), and Regional Priority (RP, 4 points), awarding a total of 110 points. Each of these categories had several prerequisites (which were mandatory for performance) and credits (which were selective for performance). In this version, credit weighting was introduced, awarding a different number of points to different credits, according to their importance in the environmental influence. In addition, the following certifications were suggested: Certified (40-49 points), Silver (50-59 points), Gold (60-79 points), and Platinum (80 points and above).

The current version, LEED-NCv4 that was introduced in 2013 [1], is very similar to the previous LEED-NCv3. It also awards 110 points in total. However, this version has nine categories: Integrative Process (IP, one point), Location and Transportation (LT, 16 points), SS (10 points), WE (11 points), EA (33 points), MR (13 points), EQ (16 points), IN (6 points), and RP (4 points). The IP category has one credit that aims to integrate energy- and water-efficient systems in an early design phase. The LT category contains transport-related credits, such as Access to Quality Transit, Bicycle Facilities, and Green Vehicles. The SS category includes credits with site-relevant requirements, such as Rainwater Management, Heat Island Reduction, and Light Pollution Reduction. The WE category contains Outdoor and Indoor Saving credits. The EA category intends to save energy through awarding such credits as Renewable Energy Production, Green Power and Carbon Offsets, and Optimize Energy Performance. The MR category requires life cycle consideration of products and materials with such credits as Building Life-cycle Impact Reduction, Building Product Disclosure and Optimization-Environmental Product Declarations, and Building Product Disclosure and Optimization-Material Ingredients. The EQ category deals with human health, including such credits as Low-Emitting Materials, Indoor Air Quality Assessment, and Thermal Comfort. The IN category has the possibility to award points for innovative sustainable building approaches and technologies. The RP category has bonus points, which can be received if regional environmental priorities were considered, and are awarded in six main categories: LT, SS, WE, EA, MR, and EQ.

It should be noted that LEED rating systems for other types of buildings, such as LEED-CI, LEED-EB, and LEED-C\&S, which (as mentioned previously) began in 2005 from the modification of LEEDv2 to different building types, also progressed through LEEDv3 to the current LEEDv4. These building type-specific LEED systems have a similar design, with some differences from the LEED-NC system credits that emphasize the relevant building type-related requirements. For example, LEED-CI in the WE category requires only indoor water saving and LEED-EB does not contain the LT category.

As previously mentioned, LEED has been successfully implemented, not only in the U.S., but also in many other foreign countries [5]. For example, Dall'O et al. [6] studied the possibility of improving the environmental quality of 14 school buildings in northern Italy according to the LEED-NCv3 system. First, the authors collected data about the actual schools' design and construction procedures that were performed at the time the buildings were constructed. Next, for each of the schools, after information about building envelopes, site conditions, local transport, water systems, and energy systems was collected, retrofit measures were suggested through application of LEED-NCv3 requirements. As a result, Dall'O et al. [6] concluded that the schools can receive Certified/Silver certification (42-54 points were awarded as candidates for LEED-NCv3) and noted that improving school sustainability in the Italian context can be successfully done with the LEED rating system. 
Sun et al. [7] studied the Chow Yei Ching (CYC) Building located at the University of Hong Kong, which underwent an LEED-EBv3-related energy efficient retrofit and was recognized as a Gold certified project (69 points) in 2015. In this project, all the stages of a green retrofit were performed. First, a walk-through assessment and energy survey of the existing building condition was conducted. Then, energy improvements regarding lighting, a chiller plant, windows, and a green roof were suggested. Finally, after implementation of these retrofitted improvements, energy measurement and verification were undertaken. As a result, it was concluded that energy consumption of the CYC building was reduced by $16 \%$, demonstrating the successful implementation of LEED-EBv3 in this green retrofit process.

Mazzola et al. [8] used the LEED Operation and Management (LEED O + Mv4) system as a framework to suggest a sustainable and green retrofit for $\mathrm{Ca}^{\prime}$ Rezzonico, a museum of 18 th century Venice (Italy). First, a green audit developed according to the prerequisites and credits of LEED O + Mv4 with regards to site-related public transport possibilities, building envelope insulation, operating energy demand, and water consumption was conducted. Then, the appropriate green retrofit measures were suggested through attempts to award LEED O+Mv4 credits in categories such as EAc4 Energy Use Improvement, WE c1 Management and Metering for water use on green areas, and EQ c4 Indoor Light Management and Metering. As a result, the methodology of using the LEED O+Mv4 system was found to be appropriate for the green retrofit of Ca' Rezzonico, which achieved Silver level certification with a total of 53 points.

In parallel with the successful implementations of LEED systems in a number of countries, many researchers have also criticized LEED certification for its inappropriateness for other countries [9]. In light of this, LEEDv3 included four RP points and alternative compliance paths, which aimed to take country-specific environmental problems into account [10].

However, these RPs were suggested by the USGBC and mainly included common water and energy saving priorities, and were not based on in-depth research of the real environmental concerns of foreign countries [9]. Such criticism was based on a qualitative analysis of the RPs that were allocated by the USGBC to Turkey, Canada, China, and Egypt [9]. As a result, Suzer [9] confirmed the inappropriateness of these RPs to the local environmental problems revealed in these countries. For example, although Turkey has high water stress, no WE credit was suggested for it by the USGBC. Another example is China, which is a very densely populated country, but does not have any SS credits among its RP credits [9].

Other issue of concern is the fixed weighing system of LEED credits, which does not allow emphasis of a country's specific concerns, and thereby does not allow the construction of real locally sustainable buildings [11]. In this respect, Suzer [9] noted that, in 2008, the U.S. Environmental Protection Agency (EPA) stated that the rigid weighting system of LEEDv3 would be converted to a flexible system in a future version, allowing the rebalancing of the weights of LEED points toward adaptation to the environmental problems of different countries. However, as is well known, LEEDv4 continues to employ the inflexible weighting system of LEEDv3 [12].

Empirical evidence of LEED-certified projects shows that, despite all of these drawbacks, LEED application in foreign countries succeeds in emphasizing the local needs of these countries. Wu et al. [13] analyzed 21 regionally-specific credits with alternative compliance paths in LEED-NCv3 certification of the following countries as examples: Brazil, the U.S., China, and Turkey. It was found that these countries employed different strategies toward LEED certification; for example, the U.S. prioritized the EA category, whereas China preferred to emphasize the SS and WE categories [13].

Pushkar [14] studied LEED-NCv3 Gold-certified projects in Finland and Sweden (northern European countries) and Turkey and Spain (southern European countries), and confirmed different strategy applications of the WE, EA, MR, and EQ categories in these countries. For example, in WEc1 (Water Efficient Landscaping), Sweden's performance was better than Finland's, and Spain's performance was better than Turkey's. 
Pushkar [15] analyzed Turkey, Spain, and Italy, which had projects awarded both LEED-CIv3 and LEED-C\&Sv3 Gold certification. This research mostly confirmed the similarity in the LEED categories' performances among these Mediterranean countries with similar environmental priorities. In particular, similarly high SS, low MR, and intermediate EQ performances were reported.

Pham et al. [16] examined LEED-NCv3 Silver, Gold, and Platinum projects certified in the southern part of Vietnam, a country with a humid tropical climate. The authors showed that most of the credits of the SS, WE, and EQ categories were performed to a high standard in this country.

These studies demonstrate empirical evidence of the possibility of selecting a preferable strategy for LEED certification in each country, thanks to the diversity of LEED-relevant credits [17]. The present study follows this research question by studying two LEED certifications (i.e., Silver and Gold) and two LEED-CI versions (i.e., v3 and v4) in parallel. The main questions that guide this study are: Will owners of Gold-certified projects receive more sustainable buildings with improvements in most of the LEED-CI categories compared to the owners of Silver-certified projects? Will the improvements in the categories of projects certified by LEED-CIv4 be more significant than the improvements in projects certified by LEED-CIv3? In order to answer these questions with maximum accuracy, two countries that are completely different in the political, economic, social, and technological contexts were evaluated, namely, the U.S. and China.

\section{Materials and Methods}

\subsection{Study Design}

To compare $\mathrm{v} 4$ with $\mathrm{v} 3$ of the LEED-CI certification projects, the following design parameters were set as criteria: The projects must belong to one rating system, one certification level, one geographical location, and, if possible, one last certified date [18-21].

Under these conditions, LEED-CIv4 and LEED-CIv3 Silver and Gold projects in China and in the U.S. had acceptable sample sizes for reliable statistical analysis according to [22]. The spatial-temporal characteristics of the LEED-CI-certified projects in China and the U.S. are shown in Table 1. To search for potentially different LEED certification strategies that may be applied in these two completely different countries, it was decided to analyze only the five basic LEED-CI categories, while excluding the RP and IN categories. Thus, information regarding the points awarded in the SS/LT, WE, EA, MR, and EQ categories of LEED-CIv4 and LEED-CIv3 Silver and Gold projects in Chinese cites and U.S. states (Table 1) was downloaded from [22] and recorded in Excel format for further statistical analysis.

Table 1. Spatial-temporal characteristics of Leadership in Energy and Environmental Design Commercial Interiors (LEED-CI)-certified projects in China and the U.S.

\begin{tabular}{|c|c|c|c|}
\hline \multicolumn{2}{|c|}{ China, LEED-CI Gold Certification } & \multicolumn{2}{|c|}{ China, LEED-CI Silver Certification } \\
\hline Version 4 & Version 3 & Version 4 & Version 3 \\
\hline Shanghai (25) 2015-2019 & Shanghai (25) 2015-2018 & Shanghai (7) 2017-2019 & Shanghai (7) 2010-2017 \\
\hline Beijing (9) 2014-2018 & Beijing (9) 2016-2018 & Beijing (6) 2017-2019 & Beijing (6) 2011-2015 \\
\hline Chengdu (2) 2019 & Chengdu (2) 2015-2018 & $\begin{array}{c}\text { Guangzhou (2) } \\
\text { 2018-2019 }\end{array}$ & $\begin{array}{c}\text { Guangzhou (2) } \\
\text { 2016-2017 }\end{array}$ \\
\hline Guangzhou (1) 2019 & Guangzhou (1) 2017 & Shenzhen (1) 2019 & Shenzhen (1) 2011 \\
\hline Hangzhou (1) 2018 & Hangzhou (1) 2016 & & \\
\hline Total (38) & Total (38) & Total (16) & Total (16) \\
\hline \multicolumn{2}{|c|}{ The U.S., LEED-CI Gold Certification } & \multicolumn{2}{|c|}{ The U.S., LEED-CI Silver Certification } \\
\hline Version 4 & Version 3 & Version 4 & Version 3 \\
\hline CA (11) 2015-2019 & CA (11) 2015-2019 & CA (13) 2018-2019 & CA (13) 2018-2019 \\
\hline NY (4) 2018-2019 & NY (4) 2018-2019 & IL (5) 2017-2019 & IL (5) 2017-2019 \\
\hline MA (4) 2018-2019 & MA (4) 2018-2019 & NY (4) 2016-2019 & NY (4) 2016-2018 \\
\hline WA (3) 2018-2019 & WA (3) 2014-2019 & TN (3) 2019 & TN (3) 2016-2019 \\
\hline
\end{tabular}


Table 1. Cont.

\begin{tabular}{cccc}
\hline IL (3) 2018 & IL (3) 2018-2019 & MA (2) 2018-2019 & MA (2) 2018-2019 \\
VA (2) 2019 & VA (2) 2018 & FL (2) 2019 & FL (2) 2019 \\
CO (2) 2017-2019 & CO (2) 2017-2019 & CO (1) 2017 & CO (1) 2017 \\
NJ (2) 2018-2019 & NJ (2) 2018 & PA (1) 2019 2019 \\
TX (2) 2019 & TX (2) 2017-2019 & NM (1) 2018 & PA (1) 2019 \\
NC (1) 2019 & NC (1) 2019 & MD (1) 2018 2018 \\
MD (1) 2019 & MD (1) 2019 & MI (1) 2019 & MD (1) 2018 \\
FL (1) 2019 & FL (1) 2019 & DC (1) 2019 & MI (1) 2018 \\
& & OH (1) 2019 & DC (1) 2018 \\
Total (36) & Total (36) & Total (37) & Total (37) \\
\hline
\end{tabular}

Notes: Number in parentheses () refers to the number of projects. CA: California; CO: Colorado; DC: District of Columbia; FL: Florida; GA: Georgia; IL: Illinois; MA: Massachusetts; MD: Maryland; MI: Michigan; MN: Minnesota; MO: Missouri; NC: North Carolina; NJ: New Jersey; NM: New Mexico; NV: Nevada; NY: New York; OH: Ohio; OR: Oregon; PA: Pennsylvania; TN: Tennessee; TX: Texas; VA: Virginia; VT: Vermont; WA: Washington.

\subsection{Statistical Analysis}

For descriptive statistics, we used the median and 25th-75th centiles instead of the mean \pm standard deviation, because the LEED data are associated with an ordinal scale. For inferential statistics, the nonparametric Cliff's $\delta$ effect size test was used instead of the parametric Cohen's d test, because the assumption of normality for the LEED data was not met. Substantive significance (effect size) instead of statistical significance ( $p$-value) was used because statistical significance depends on the sample size, whereas the effect size does not [18]. According to Cliff [23], Cliff's $\delta$ test measures the difference magnitude between two distributions.

Cliff's $\delta$ (p. 495, [23]) is expressed as:

$$
\delta=\#\left(x_{1}>x_{2}\right)-\#\left(x_{1}<x_{2}\right) /\left(n_{1} n_{2}\right)
$$

where $\mathrm{x}_{1}$ and $\mathrm{x}_{2}$ are the scores within group 1 and group 2, respectively; $\mathrm{n}_{1}$ and $\mathrm{n}_{2}$ are the sizes of the sample groups, group 1 and group 2, respectively; and \# indicates the number of times.

Cliff's $\delta$ ranges between -1 and +1 ; positive $(+)$ values indicate that group 1 is larger than group 2 , 0 indicates equality or overlap, and negative (-) values indicate that group 2 is larger than group 1 [23]. Cliff's $\delta$ test was used to evaluate $\left(\delta_{1}\right)$ the difference between the achieved and the possible points and $\left(\delta_{2}\right)$ the difference between Silver and Gold projects, where $\delta_{1}$ is $1-|\delta|$ and $\delta_{2}$ is $1 \leq \delta \geq-1$.

According to Romano et al. [24], the effect size is considered to be (i) negligible if $|\delta|<0.147$, (ii) small if $0.147 \leq|\delta|<0.33$, (iii) medium if $0.33 \leq|\delta|<0.474$, and (iv) large if $|\delta| \geq 0.474$.

To evaluate the effect size between two LEED binary (" 0 or 1 ") credits, we used the natural logarithm of the odds ratio $(\ln \theta)$. According to Haddock et al. [25], if $\ln \theta$ or $\log$ odds ratio is equal to 0 , then there is no association between two LEED binary credits. Positive $(+)$ values indicate that group 1 is larger than group 2 and negative (-) values indicate that group 2 is larger than group 1 . The degree of association between binary outcomes was adapted from the study by Chen et al. [26]. The effect size thresholds of the absolute $\ln \theta(\lfloor\ln \theta\rfloor)$ are considered to be 0.51 (small), 1.24 (medium), and 1.90 (large).

In general, the terms high, medium, or low performance, which are used in the results and discussion sections, correspond to a large, medium, or small value of the effect size, respectively. It should be noted that the effect size does not provide "iron-clad criteria" [27] but only a general rule of thumb that might be followed in the absence of knowledge of the area [28]. 


\section{Results and Discussion}

\subsection{Sustainable Sites and Location and Transportation}

In LEED-CIv3 (Table 2), three credits (SSc2: Development Density and Community Connectivity; SSc3.1: Alternative Transportation-Public Transportation Access; SSc3.2: Alternative Transportation-Bicycle Storage and Changing Rooms) were similarly performed by the Chinese and the U.S. Silver and Gold projects: SSc2 and SSc3.1 to a high standard and SSc3.2 to a low standard in the Silver projects, and to a medium standard in the Gold projects. The high performance of SSc2 and SSc3.1 is not surprising, because the restriction of virgin land development and transport-related greenhouse gas emissions is important for the urban, highly populated Chinese and U.S. cites that were evaluated in this study.

Table 2. LEED-CI v3 Sustainable Sites (SS) credits category: The median and 25th-75th centiles and Cliff's effect size $\left(\delta_{1}\right)$ of the difference between the achieved and the possible points, and $\left(\delta_{2}\right)$ of the difference between Silver and Gold projects in China and the U.S.

\begin{tabular}{|c|c|c|c|c|c|}
\hline \multirow{2}{*}{ Credit/Category } & \multirow{2}{*}{ Country/ $/ \delta_{1}$} & \multirow{2}{*}{$\begin{array}{c}\text { Possible } \\
\text { Points }\end{array}$} & \multicolumn{2}{|c|}{ Achieved Points } & \multirow{2}{*}{$\delta_{2}$} \\
\hline & & & Silver & Gold & \\
\hline SSc1 Site selection & $\begin{array}{l}\text { China } \delta_{1} \\
\text { The U.S. } \delta_{1}\end{array}$ & 5 & $\begin{array}{l}1.01 .0-2.0 \\
0.06 \\
3.01 .0-5.0 \\
\quad 0.38\end{array}$ & $\begin{array}{c}3.02 .0-5.0 \\
0.32 \\
4.01 .0-5.0 \\
\mathbf{0 . 4 7}\end{array}$ & $\begin{array}{c}-0.48 \\
X \\
-0.12 \\
X\end{array}$ \\
\hline $\begin{array}{l}\text { SSc2 Development } \\
\text { Density and } \\
\text { Community } \\
\text { Connectivity }\end{array}$ & The U.S. $\delta_{1}$ & 6 & $\begin{array}{c}6.06 .0-6.0 \\
\mathbf{0 . 9 4} \\
6.06 .0-6.0 \\
\mathbf{0 . 8 6}\end{array}$ & $\begin{array}{c}6.06 .0-6.0 \\
\mathbf{1 . 0 0} \\
6.06 .0-6.0 \\
\mathbf{0 . 9 2}\end{array}$ & $\begin{array}{c}-0.06 \\
X \\
-0.05 \\
X\end{array}$ \\
\hline $\begin{array}{c}\text { SSc3.1 Alternative } \\
\text { Transportation- } \\
\text { Public Transportation } \\
\text { Access }\end{array}$ & The U.S. $\delta_{1}$ & 6 & $\begin{array}{c}6.06 .0-6.0 \\
\mathbf{1 . 0 0} \\
6.06 .0-6.0 \\
\mathbf{0 . 8 6}\end{array}$ & $\begin{array}{c}6.06 .0-6.0 \\
\mathbf{1 . 0 0} \\
6.06 .0-6.0 \\
\mathbf{0 . 9 2}\end{array}$ & $\begin{array}{c}0.00 \\
X \\
-0.05 \\
X\end{array}$ \\
\hline $\begin{array}{l}\text { SSc3.2 Alternative } \\
\text { Transportation- } \\
\text { Bicycle Storage and } \\
\text { Changing Rooms }\end{array}$ & The U.S. $\delta_{1}$ & 2 & $\begin{array}{c}0.00 .0-0.0 \\
0.12 \\
0.00 .0-2.0 \\
0.27\end{array}$ & $\begin{array}{c}0.00 .0-2.0 \\
\quad 0.34 \\
0.00 .0-2.0 \\
\quad 0.42\end{array}$ & $\begin{array}{c}-0.22 \\
X \\
-0.15 \\
X\end{array}$ \\
\hline $\begin{array}{l}\text { SSc3.3 Alternative } \\
\text { Transportation- } \\
\text { Parking Availability }\end{array}$ & The U.S. $\delta_{1}$ & 2 & $\begin{array}{c}2.00 .0-2.0 \\
\mathbf{0 . 8 7} \\
0.00 .0-2.0 \\
\mathbf{0 . 4 1}\end{array}$ & $\begin{array}{c}2.02 .0-2.0 \\
\mathbf{0 . 9 7} \\
0.00 .0-2.0 \\
\mathbf{0 . 3 9}\end{array}$ & $\begin{array}{l}-0.29 \\
X \\
0.02 \\
X\end{array}$ \\
\hline SS Total & $\begin{array}{l}\text { China } \\
\text { The U.S. }\end{array}$ & 21 & $\begin{array}{l}15.015 .0-16.0 \\
15.011 .5-17.0\end{array}$ & $\begin{array}{l}18.016 .0-19.0 \\
17.013 .5-18.5\end{array}$ & $\begin{array}{l}-\mathbf{0 . 6 1} \\
-0.15\end{array}$ \\
\hline
\end{tabular}

Notes: The $\delta$ effect size is considered to be (i) negligible if $|\delta|<0.147$, (ii) small if $0.147 \leq|\delta|<0.33$, (iii) medium if 0.33 $\leq|\delta|<0.474$, and (iv) large if $|\delta| \geq 0.474$.

In the Silver and Gold certifications, SSc1 (Site Selection) had low performance in the Chinese projects and medium performance in the U.S. projects, whereas SSc3.3 (Alternative Transportation-Parking Availability) had high performance in the Chinses projects and medium performance in the U.S. projects.

In LEED-CIv4 (Table 3), the Chinese projects were successful in three credits (LTc2: Surrounding Density and Diverse Uses; LTc3: Access to Quality Transit; LTc5: Reduced Parking Footprint), which had high performance in both the Silver and Gold projects. In contrast, in the U.S. projects, only one credit (LTc2) had high performance in both the Silver and Gold projects, and the other two (LTc3 and LTc5) had high performance in the Gold projects only. Thus, these three virgin land and transport-related credits continued the tendency of high performance that was previously observed for the SS category. It should be noted that, in China, most of the examined projects (particularly Gold projects) were located in Shanghai (Table 1). This highly compact megacity accounts for 24.15 million 
permanent residents [29]. Therefore, the residents of Shanghai have restrictions on private car ownership, while public transportation is highly developed in this megacity [30].

In addition, LTc4 (Bicycle Facilities) continued the tendency of low and medium performance in the Silver and Gold projects, respectively, in both the Chinese cities and the U.S. states that were previously noted for the SS category. It should be remembered that, in the U.S., most of the studied projects were located in California (Table 1). The building sector in California operates under strong local energy and environmental regulations. In particular, with regards to the low performing bicycle-related credits (SSc3.2 and LTc4, Tables 2 and 3, respectively), California's Code of Regulations (Title 24, Section 5.106.4 Bicycle parking [31]) also requires that a project should provide secure bicycle parking for 5 percent of the tenants, similar to the requirements presented in these credits. However, the Californian code prescribes any requirements to have showers (which is part of SSc3.2 and LTc4 credit requirements). This might be considered a difficulty in achievement of these credits.

It is worth mentioning that the LT category suggests an additional approach to achieve this credit: To use an existing building development with LEED for Neighborhood Development certification for the location of the design project [12]. Nevertheless, this approach was not popular in either the Chinese or the U.S. projects, which both preferred the conventional approach of gaining several separate credits, such as Surrounding Density and Diverse Uses, Access to Quality Transit, Bicycle Facilities, and Reduced Parking Footprint (Table 3).

As a result, in both SS (LEED-CIv3) and LT (LEED-CIv4), the Chinese Silver and Gold projects performed to a higher standard compared to the U.S. Silver and Gold projects. Moreover, in the Chinese projects, the difference between Silver and Gold SS performance (LEED-CIv3) was improved in LT [12], in which both the Silver and Gold projects had similar high performance. This is consistent with the results of Suzer [9], who confirmed that SS is an important category for China, and with the results presented by Wu et al. [13], who evaluated LEED-NCv3 projects and reported that the SS category is implemented better in China that in the U.S.

Table 3. LEED-CI v4 Location and Transportation (LT) credits category: The median and 25th-75th centiles and Cliff's effect size $\left(\delta_{1}\right)$ of the difference between the achieved and the possible points, and $\left(\delta_{2}\right)$ or $\ln \theta$ of the difference between Silver and Gold projects in China and the U.S.

\begin{tabular}{|c|c|c|c|c|c|}
\hline \multirow{2}{*}{ Credit/Category } & \multirow{2}{*}{ Country/ $\delta_{1}$} & \multirow{2}{*}{$\begin{array}{l}\text { Possible } \\
\text { Points }\end{array}$} & \multicolumn{2}{|c|}{ Achieved Points } & \multirow{2}{*}{$\delta_{2} / \ln \theta$} \\
\hline & & & Silver & Gold & \\
\hline \multirow{4}{*}{$\begin{array}{l}\text { LTc2 Surrounding Density } \\
\text { and Diverse Uses }\end{array}$} & \multirow{2}{*}{ China $\delta_{1}$} & \multirow{4}{*}{8} & $8.08 .0-8.0$ & $8.08 .0-8.0$ & 0.03 \\
\hline & & & 1.00 & 0.97 & $X$ \\
\hline & \multirow{2}{*}{ The U.S. $\delta_{1}$} & & $8.05 .0-8.0$ & $8.05 .0-8.0$ & -0.08 \\
\hline & & & 0.68 & 0.72 & $X$ \\
\hline \multirow{4}{*}{$\begin{array}{c}\text { LTc3 Access to Quality } \\
\text { Transit }\end{array}$} & \multirow{2}{*}{ China $\delta_{1}$} & \multirow{4}{*}{7} & $7.07 .0-7.0$ & $7.07 .0-7.0$ & 0.03 \\
\hline & & & 1.00 & 0.97 & X \\
\hline & \multirow{2}{*}{ The U.S. $\delta_{1}$} & & $6.00 .0-7.0$ & $7.06 .0-7.0$ & -0.27 \\
\hline & & & 0.43 & 0.68 & X \\
\hline \multirow{4}{*}{ LTc4 Bicycle Facilities } & \multirow{2}{*}{ China $\delta_{1}$} & \multirow{4}{*}{1} & $0.00 .0-0.5$ & $0.00 .0-1.0$ & $-0.99^{1}$ \\
\hline & & & 0.25 & 0.47 & X \\
\hline & \multirow{2}{*}{ The U.S. $\delta_{1}$} & & $0.00 .0-1.0$ & $0.00 .0-1.0$ & $-0.17^{1}$ \\
\hline & & & 0.30 & 0.33 & X \\
\hline \multirow{4}{*}{$\begin{array}{l}\text { LTc5 Reduced Parking } \\
\text { Footprint }\end{array}$} & \multirow{2}{*}{ China $\delta_{1}$} & \multirow{4}{*}{2} & $2.02 .0-2.0$ & $2.02 .0-2.0$ & -0.01 \\
\hline & & & 0.94 & 0.95 & X \\
\hline & \multirow{2}{*}{ The U.S. $\delta_{1}$} & & $0.00 .0-2.0$ & $2.00 .0-2.0$ & -0.29 \\
\hline & & & 0.35 & 0.68 & X \\
\hline \multirow{2}{*}{ LT Total } & China & \multirow{2}{*}{18} & $17.017 .0-17.5$ & $17.017 .0-18.0$ & -0.17 \\
\hline & The U.S. & & $14.07 .0-16.3$ & $17.011 .0-17.0$ & -0.32 \\
\hline
\end{tabular}

Notes: The $\delta$ effect size is considered to be (i) negligible if $|\delta|<0.147$, (ii) small if $0.147 \leq|\delta|<0.33$, (iii) medium if $0.33 \leq|\delta|<0.474$, and (iv) large if $|\delta| \geq 0.474 .{ }^{1}$ The $|\ln \theta|$ effect size thresholds are considered to be 0.51 (small), 1.24 (medium), and 1.90 (large). 


\subsection{Water Efficiency}

In both the LEED-CI v3 and v4 certifications (Table 4), the Chinese Silver and Gold projects performed to a higher standard compared to the U.S. Silver and Gold projects. In LEED-CIv3, the Chinese and US Gold projects performed better than their Silver projects, whereas, in LEED-CIv4, the Chinese and U.S. projects performed similarly in both the Silver and Gold certifications.

It should be highlighted that almost all of the Chinese LEED-CI v3 and v4 Gold projects achieved scores of 11 or 12, i.e., maximum points (Table 4). Such results were expected, because the projects analyzed in this study were located in North China (Beijing) and East China (Shanghai), as well as in South Central China (Guangzhou and Shenzhen) and South West China (Chengdu), which experience extreme or moderate water stress [32]. Moderate and extreme water stress was defined by Zhao et al. [33] as $40-100 \%$ of the water requirements relative to the renewable fresh water.

As was noted previously, most of the evaluated projects in China were located in Shanghai and most of the evaluated projects in the U.S. were located in California. Thus, it should be added that Shanghai is a huge consumer of goods produced (with high water consumption) in other provinces. Thus, Shanghai has 79\% virtual water, which arrives from other provinces due to these water-consuming goods [33]. Overall, this megacity has a water shortage problem and water saving practices are still urgently required in its construction sector.

With respect to California, this state should save water according to California's Code of Regulations (Title 24, Section 4.3 Water efficiency and conservation [31]), which is equivalent to LEED-CI v3 and $\mathrm{v} 4 \mathrm{WE}$ prerequisite requirements to reduce potable water by $20 \%$ from the calculated baseline [34]. According to the results of the WE category (Table 4 ), in the US, only $35 \%$ (6 points) of water saving was achieved, which is an achievement only slightly above the requirements of California's Code of Regulations. This means that low requirements of local water codes, such as the considered example of California's Code of Regulations, may serve as an obstacle to the high achievement of water-related credits in the US.

Table 4. LEED-CI v3 and v4 Indoor Water Use Reduction (WEc1) credits category: The median and 25th-75th centiles and Cliff's effect size $\left(\delta_{1}\right)$ of the difference between the achieved and the possible points, and $\left(\delta_{2}\right)$ of the difference between Silver and Gold projects in China and the U.S.

\begin{tabular}{|c|c|c|c|c|c|}
\hline \multirow{2}{*}{ Credits } & \multirow{2}{*}{ Country $/ \delta_{1}$} & \multirow{2}{*}{$\begin{array}{c}\text { Possible } \\
\text { Points }\end{array}$} & \multicolumn{2}{|c|}{ Achieved Points } & \multirow{2}{*}{$\delta_{2}$} \\
\hline & & & Silver & Gold & \\
\hline \multirow{4}{*}{$\begin{array}{c}\text { WEc1 Water Use } \\
\text { Reduction (LEED-CI v3) }\end{array}$} & \multirow{2}{*}{ China $\delta_{1}$} & \multirow{4}{*}{11} & $9.56 .0-11.0$ & $11.011 .0-11.0$ & -0.34 \\
\hline & & & 0.50 & 0.79 & X \\
\hline & \multirow{2}{*}{ The U.S. $\delta_{1}$} & & $6.00 .0-8.0$ & $8.08 .0-11.0$ & -0.43 \\
\hline & & & 0.19 & 0.47 & $X$ \\
\hline \multirow{4}{*}{$\begin{array}{l}\text { WEc1 Indoor Water Use } \\
\text { Reduction (LEED-CI v4) }\end{array}$} & \multirow{2}{*}{ China $\delta_{1}$} & \multirow{4}{*}{12} & $10.08 .0-12.0$ & $12.010 .0-12.0$ & -0.23 \\
\hline & & & 0.44 & 0.68 & X \\
\hline & \multirow{2}{*}{ The U.S. $\delta_{1}$} & & $6.04 .0-6.0$ & $6.06 .0-8.0$ & -0.27 \\
\hline & & & 0.00 & 0.03 & X \\
\hline
\end{tabular}

Notes: The $\delta$ effect size is considered to be (i) negligible if $|\delta|<0.147$, (ii) small if $0.147 \leq|\delta|<0.33$, (iii) medium if 0.33 $\leq|\delta|<0.474$, and (iv) large if $|\delta| \geq 0.474$.

\subsection{Energy and Atmosphere}

In the LEED-CIv3 certification (Table 5), in China, EAc1.4 (Optimize Energy Performance-Equipment and Appliances) and EAc4 (Green Power) had high performance in both the Silver and Gold projects, while EAc1.1 (Optimize Energy Performance-Lighting power) and EAc3 (Measurement and Verification) had high performance in the Gold projects only; all other EA credits had low performance in both the Silver and Gold projects. In the U.S. (Table 5), three credits (EAc1.1: Optimize Energy performance-Lighting power; EAc1.4; and EAc4) had high performance in both the Silver and Gold projects, and one credit (EAc2: Enhanced Commissioning) had high performance in the Gold projects only; all other credits had low performance in both the Silver and Gold projects. 
Table 5. LEED-CIv3 Energy and Atmosphere (EA) credits category: The median and 25th-75th centiles and Cliff's effect size $\left(\delta_{1}\right)$ of the difference between the achieved and the possible points, and $\left(\delta_{2}\right)$ of the difference between Silver and Gold projects in China and the U.S.

\begin{tabular}{|c|c|c|c|c|c|}
\hline \multirow{2}{*}{ Credit/Category } & \multirow{2}{*}{ Country $/ \delta_{1}$} & \multirow{2}{*}{$\begin{array}{l}\text { Possible } \\
\text { Points }\end{array}$} & \multicolumn{2}{|c|}{ Achieved Points } & \multirow[b]{2}{*}{$\delta_{2}$} \\
\hline & & & Silver & Gold & \\
\hline \multirow{4}{*}{$\begin{array}{c}\text { EAc1.1 Optimize Energy } \\
\text { Performance-Lighting } \\
\text { Power }\end{array}$} & \multirow{2}{*}{ China $\delta_{1}$} & \multirow{4}{*}{5} & $2.02 .0-4.0$ & $5.03 .0-5.0$ & -0.41 \\
\hline & & & 0.19 & 0.55 & $X$ \\
\hline & \multirow{2}{*}{ The U.S. $\delta_{1}$} & & $5.03 .0-5.0$ & $5.03 .0-5.0$ & 0.05 \\
\hline & & & 0.70 & 0.68 & $x$ \\
\hline \multirow{4}{*}{$\begin{array}{c}\text { EAc1.2 Optimize Energy } \\
\text { Performance-Lighting } \\
\text { Controls }\end{array}$} & \multirow{2}{*}{ China $\delta_{1}$} & \multirow{4}{*}{3} & $0.00 .0-1.0$ & $0.50 .0-2.0$ & -0.17 \\
\hline & & & 0.16 & 0.19 & $X$ \\
\hline & \multirow{2}{*}{ The U.S. $\delta_{1}$} & & $1.00 .0-2.0$ & $1.01 .0-2.0$ & -0.27 \\
\hline & & & 0.05 & 0.08 & X \\
\hline \multirow{4}{*}{$\begin{array}{l}\text { EAc1.3 Optimize Energy } \\
\text { Performance-HVAC }\end{array}$} & \multirow{2}{*}{ China $\delta_{1}$} & \multirow{4}{*}{10} & $0.00 .0-5.0$ & $0.00 .0-5.0$ & 0.11 \\
\hline & & & 0.00 & 0.00 & X \\
\hline & \multirow{2}{*}{ The U.S. $\delta_{1}$} & & $0.00 .0-5.0$ & $0.00 .0-5.0$ & -0.17 \\
\hline & & & 0.03 & 0.11 & X \\
\hline \multirow{4}{*}{$\begin{array}{l}\text { EAc1.4 Optimize Energy } \\
\text { Performance-Equipment } \\
\text { and Appliances }\end{array}$} & \multirow{2}{*}{ China $\delta_{1}$} & \multirow{4}{*}{4} & $3.51 .0-4.0$ & $3.53 .0-4.0$ & -0.08 \\
\hline & & & 0.50 & 0.50 & X \\
\hline & \multirow{2}{*}{ The U.S. $\delta_{1}$} & & $4.01 .7-4.0$ & $4.01 .0-4.0$ & 0.05 \\
\hline & & & 0.62 & 0.56 & $X$ \\
\hline \multirow{4}{*}{$\begin{array}{l}\text { EAc2 Enhanced } \\
\text { Commissioning }\end{array}$} & \multirow{2}{*}{ China $\delta_{1}$} & \multirow{4}{*}{5} & $0.00 .0-0.0$ & $0.00 .0-5.0$ & -0.30 \\
\hline & & & 0.12 & 0.42 & X \\
\hline & \multirow{2}{*}{ The U.S. $\delta_{1}$} & & $0.00 .0-5.0$ & $5.05 .0-5.0$ & -0.48 \\
\hline & & & 0.38 & 0.86 & $X$ \\
\hline \multirow{4}{*}{$\begin{array}{l}\text { EAc3 Measurement and } \\
\text { Verification }\end{array}$} & \multirow{2}{*}{ China $\delta_{1}$} & \multirow{4}{*}{5} & $0.00 .0-4.0$ & $5.02 .0-5.0$ & -0.38 \\
\hline & & & 0.25 & 0.55 & $X$ \\
\hline & \multirow{2}{*}{ The U.S. $\delta_{1}$} & & $0.00 .0-0.5$ & $0.00 .0-3.0$ & -0.20 \\
\hline & & & 0.19 & 0.22 & $x$ \\
\hline \multirow{4}{*}{ EAc4 Green Power } & China $\delta$ & & $5.00 .0-5.0$ & $2.50 .0-5.0$ & 0.06 \\
\hline & Cnina o 1 & 5 & 0.56 & 0.50 & $X$ \\
\hline & & 5 & $5.00 .0-5.0$ & $5.02 .5-5.0$ & -0.16 \\
\hline & the U.S. $0_{1}$ & & 0.59 & 0.75 & X \\
\hline EA Total & China & 3 & $13.011 .0-15.5$ & $17.016 .0-19.0$ & -0.62 \\
\hline EA lotal & The U.S. & 37 & $15.011 .0-18.5$ & $21.018 .5-23.5$ & -0.58 \\
\hline
\end{tabular}

Notes: The $\delta$ effect size is considered to be (i) negligible if $|\delta|<0.147$, (ii) small if $0.147 \leq|\delta|<0.33$, (iii) medium if 0.33 $\leq|\delta|<0.474$, and (iv) large if $|\delta| \geq 0.474$.

In the LEED-CIv4 certification (Table 6), in the Chinese projects, EAc4 (Enhanced Refrigerant Management) had high performance in the Silver and Gold projects, and in the U.S. projects, EAc5 (Green Power and Carbon Offsets) had high performance in the Silver and Gold projects, while EAc4 (Enhanced Refrigerant Management) had medium performance in the Silver and Gold projects; all other EA credits of the Chinese and U.S. projects had low performance.

In both LEED-CI v3 and v4 (Tables 5 and 6), this resulted in higher U.S. Silver and Gold-related EA category performance compared to the Chinese Silver and Gold projects. In addition, in both LEED-CI v3 and v4, in the EA category, the Gold projects performed significantly better than the Silver projects. It should be noted that EAc6 (Optimize Energy Performance; Table 6) has the largest share of available points, i.e., 25 points, of the total EA-relevant 38 points. Therefore, this credit provides significant potential for increasing the total project score and is usually used for Gold and Platinum certifications, because these levels require a large number of points [35].

With respect to the U.S., California, in which most of the evaluated projects were located, is a state with the strongest local energy efficiency standards and green building codes [36]. For example, in 2017 California adopted the strictest current version of the energy national code: Energy Standard for Buildings Except Low-Rise Residential Buildings, ASHRAE 90.1-2016. In addition, the construction sector operates according to Building Energy Efficiency Standards (Title 24) and the California Green Building Standards Code [34]. 
With respect to China, Shanghai, in which most of the evaluated projects were located, is a megacity with a newly emerging and strong energy policy. For example, the Green Electricity Scheme was launched in 2006 in Shanghai; however, this was unsuccessful in its implementation due to the high prices of green electricity produced by local wind farms and the lack of awareness of the population about the usefulness of this renewable energy source [37].

Similar EA results were confirmed by other authors. Wu et al. [13] analyzed LEED-NCv3 projects and confirmed that the EA category was better performed in the U.S. than in China. High performance achievement of the EA category in U.S. LEED-CIv4 projects was also confirmed by Pushkar [38], who stated that EA achievements increased from level to level with the following median \pm interquartile range (IQR, 25th-75th percentiles) achieved points: $12.0 \pm 4.0,14.0 \pm 7.5,22.5 \pm 13.0$, and $31.5 \pm 7.5$ in the Certified, Silver, Gold, and Platinum projects, respectively.

Table 6. LEED-CIv4 Energy and Atmosphere (EA) credits category: The median and 25th-75th centiles and Cliff's effect size $\left(\delta_{1}\right)$ of the difference between the achieved and the possible points, and $\left(\delta_{2}\right)$ or $\ln \theta$ of the difference between Silver and Gold projects in China and the U.S.

\begin{tabular}{|c|c|c|c|c|c|}
\hline \multirow{2}{*}{ Credit/Category } & \multirow{2}{*}{ Country/ $\delta_{1}$} & \multirow{2}{*}{$\begin{array}{c}\text { Possible } \\
\text { Points }\end{array}$} & \multicolumn{2}{|c|}{ Achieved Points } & \multirow{2}{*}{$\delta_{2} / \ln \theta$} \\
\hline & & & Silver & Gold & \\
\hline & & \multirow{4}{*}{5} & $4.00 .0-4.0$ & $4.04 .0-4.0$ & -0.20 \\
\hline EAc1 Enhanced & China $\delta_{1}$ & & 0.00 & 0.05 & X \\
\hline Commissioning & \multirow{2}{*}{ The U.S. $\delta_{1}$} & & $4.04 .0-4.0$ & $4.04 .0-5.0$ & -0.27 \\
\hline & & & 0.14 & 0.28 & X \\
\hline EAc2 & \multirow{2}{*}{ China $\delta_{1}$} & \multirow{4}{*}{2} & $0.50 .0-1.0$ & $1.00 .0-1.0$ & -0.28 \\
\hline Advanced & & & 0.00 & 0.24 & X \\
\hline Energy & \multirow{2}{*}{ The U.S. $\delta_{1}$} & & $0.00 .0-1.0$ & $1.00 .0-1.5$ & -0.14 \\
\hline Metering & & & 0.16 & 0.25 & X \\
\hline EAc3 & \multirow{2}{*}{ China $\delta_{1}$} & \multirow{4}{*}{3} & $0.00 .0-0.0$ & $0.00 .0-0.0$ & 0.00 \\
\hline Renewable & & & 0.00 & 0.00 & $X$ \\
\hline Energy & \multirow{2}{*}{ The U.S. $\delta_{1}$} & & $0.00 .0-0.0$ & $0.00 .0-0.0$ & -0.06 \\
\hline Production & & & 0.08 & 0.14 & X \\
\hline \multirow{4}{*}{$\begin{array}{l}\text { EAc4 Enhanced } \\
\text { Refrigerant } \\
\text { Management }\end{array}$} & \multirow{2}{*}{ China $\delta_{1}$} & \multirow{4}{*}{1} & $1.00 .5-1.0$ & $1.00 .5-1.0$ & $-0.99^{1}$ \\
\hline & & & 0.75 & 0.82 & X \\
\hline & \multirow{2}{*}{ The U.S. $\delta_{1}$} & & 0.00 .01 .0 & 0.00 .01 .0 & $-0.17^{1}$ \\
\hline & & & 0.43 & 0.36 & X \\
\hline & & \multirow{4}{*}{2} & $0.00 .0-0.0$ & $0.00 .0-2.0$ & -0.15 \\
\hline EAc5 Green & China $\delta_{1}$ & & 0.19 & 0.34 & X \\
\hline Power and & \multirow{2}{*}{ The U.S. $\delta_{1}$} & & $2.00 .0-2.0$ & $2.01 .5-2.0$ & -0.24 \\
\hline Carbon Ottsets & & & 0.51 & 0.75 & X \\
\hline & & \multirow{4}{*}{25} & $8.07 .5-8.0$ & $10.08 .0-12.0$ & -0.55 \\
\hline $\begin{array}{c}\text { EAc6 Uptimize } \\
\text { Fnerov }\end{array}$ & China $\delta_{1}$ & & 0.00 & 0.00 & $X$ \\
\hline Energy & The US $\delta_{1}$ & & $9.07 .0-15.5$ & $15.010 .0-21.5$ & -0.40 \\
\hline Performance & Ine U.S. $\delta_{1}$ & & 0.05 & 0.14 & $x$ \\
\hline \multirow{2}{*}{ EA Total } & China & \multirow{2}{*}{38} & $11.510 .0-13.0$ & $16.014 .0-18.0$ & -0.77 \\
\hline & The U.S. & & $14.012 .0-20.8$ & $22.516 .0-29.0$ & -0.52 \\
\hline
\end{tabular}

Notes: The $\delta$ effect size is considered to be (i) negligible if $|\delta|<0.147$, (ii) small if $0.147 \leq|\delta|<0.33$, (iii) medium if $0.33 \leq|\delta|<0.474$, and (iv) large if $|\delta| \geq 0.474 .{ }^{1}$ The $|\ln \theta|$ effect size thresholds are considered to be 0.51 (small), 1.24 (medium), and 1.90 (large).

\subsection{Materials and Resources}

In LEED-CIv3 (Table 7), in the Chinese projects, almost all of the MR credits had low performance in both the Silver and Gold projects, with the exception of MRc2 (Construction Waste Management), which had high performance in both the Silver and Gold certifications, as well as MRc4 (Recycled Content) and MRc5 (Regional Materials), which had medium performance in both the Silver and Gold certifications. In the U.S. projects, almost all of the MR credits also had low performance in both the Silver and Gold projects, with the exception of MRc1.1 (Tenant Space-Long-term commitment) and MRc2, which had high performance in both the Silver and Gold certifications, and MRc4, which had 
medium performance in the Gold certification only. This resulted in similar low Chinese and U.S. Silver and Gold MR category performances.

Table 7. LEED-CIv3 Materials and Resources (MR) credits category: The median and 25th-75th centiles and Cliff's effect size $\left(\delta_{1}\right)$ of the difference between the achieved and the possible points, and $\left(\delta_{2}\right)$ or $\ln \theta$ of the difference between Silver and Gold projects in China and the U.S.

\begin{tabular}{|c|c|c|c|c|c|}
\hline \multirow{2}{*}{ Credit/Category } & \multirow{2}{*}{ Country $/ \delta_{1}$} & \multirow{2}{*}{$\begin{array}{l}\text { Possible } \\
\text { Points }\end{array}$} & \multicolumn{2}{|c|}{ Achieved Points } & \multirow{2}{*}{$\delta_{2} / \ln \theta$} \\
\hline & & & Silver & Gold & \\
\hline & & \multirow{4}{*}{1} & $0.00 .0-0.5$ & $0.00 .0-1.0$ & $-0.44^{1}$ \\
\hline & China $\delta_{1}$ & & 0.25 & 0.34 & X \\
\hline \multirow{2}{*}{ Long-term Commitment } & \multirow{2}{*}{ The U.S. $\delta_{1}$} & & $1.00 .0-1.0$ & $1.01 .0-1.0$ & $-0.88^{1}$ \\
\hline & & & 0.66 & 0.83 & $x$ \\
\hline MRc1.2 Building & \multirow[b]{2}{*}{ China $\delta_{1}$} & \multirow{4}{*}{2} & $0.00 .0-0.0$ & $0.00 .0-0.0$ & 0.10 \\
\hline Reuse-Maintain & & & 0.12 & 0.00 & $X$ \\
\hline Interior Nonstructural & \multirow{2}{*}{ The U.S. $\delta_{1}$} & & $0.00 .0-0.0$ & $0.00 .0-0.0$ & 0.03 \\
\hline Elements & & & 0.08 & 0.00 & $x$ \\
\hline \multirow{4}{*}{$\begin{array}{l}\text { MRc2 Construction } \\
\text { Waste Management }\end{array}$} & \multirow{2}{*}{ China $\delta_{1}$} & \multirow{4}{*}{2} & $2.00 .0-2.0$ & $2.02 .0-2.0$ & -0.16 \\
\hline & & & 0.62 & 0.79 & $X$ \\
\hline & \multirow{2}{*}{ The U.S. $\delta_{1}$} & & $2.01 .0-2.0$ & $2.01 .0-2.0$ & -0.04 \\
\hline & & & 0.59 & 0.68 & $X$ \\
\hline \multirow{4}{*}{ MRc3.1 Materials Reuse } & \multirow{2}{*}{ China $\delta_{1}$} & \multirow{4}{*}{2} & $0.00 .0-0.0$ & $0.00 .0-0.0$ & 0.00 \\
\hline & & & 0.00 & 0.00 & $x$ \\
\hline & \multirow{2}{*}{ The U.S. $\delta_{1}$} & & $0.00 .0-0.0$ & $0.00 .0-0.0$ & 0.03 \\
\hline & & & 0.05 & 0.03 & $X$ \\
\hline \multirow{4}{*}{$\begin{array}{c}\text { MRc3.2 Materials } \\
\text { Reuse-Furniture and } \\
\text { Furnishings }\end{array}$} & \multirow{2}{*}{ China $\delta_{1}$} & \multirow{4}{*}{1} & $0.00 .0-0.5$ & $0.00 .0-0.0$ & $1.04^{1}$ \\
\hline & & & 0.25 & 0.11 & X \\
\hline & \multirow{2}{*}{ The U.S. $\delta_{1}$} & & $0.00 .0-0.0$ & $0.00 .0-0.0$ & $1.45^{1}$ \\
\hline & & & 0.11 & 0.03 & $X$ \\
\hline \multirow{4}{*}{ MRc4 Recycled Content } & \multirow{2}{*}{ China $\delta_{1}$} & \multirow{4}{*}{2} & $1.00 .0-2.0$ & $1.01 .0-2.0$ & -0.15 \\
\hline & & & 0.37 & 0.39 & X \\
\hline & The UIS $\delta_{1}$ & & $1.00 .0-2.0$ & $1.00 .0-2.0$ & -0.07 \\
\hline & Ine U.S. $\delta_{1}$ & & 0.31 & 0.41 & $x$ \\
\hline & & & $1.00 .0-2.0$ & $1.01 .0-2.0$ & -0.20 \\
\hline MRc5 Regional Materials & China $\delta_{1}$ & & 0.37 & 0.42 & X \\
\hline Miкç Kegional inaterials & & 2 & $0.00 .0-1.0$ & $0.00 .0-1.0$ & -0.11 \\
\hline & The U.S. $\delta_{1}$ & & 0.17 & 0.19 & X \\
\hline & China $\delta$ & & $0.00 .0-0.0$ & $0.00 .0-0.0$ & $-0.03^{1}$ \\
\hline MRc6 Rapidly & China $\delta_{1}$ & 1 & 0.00 & 0.03 & X \\
\hline Renewable Materials & The U.S. $\delta_{1}$ & 1 & $0.00 .0-0.0$ & $0.00 .0-0.0$ & $-0.06^{1}$ \\
\hline & The U.S. $\delta_{1}$ & & 0.00 & 0.06 & X \\
\hline & & & $0.00 .0-0.0$ & $0.00 .0-0.0$ & $0.00^{1}$ \\
\hline & China $\delta_{1}$ & & 0.00 & 0.00 & $X$ \\
\hline MRc7 Certified Wood & The UIS $\delta_{1}$ & 1 & $0.00 .0-0.0$ & $0.00 .0-0.0$ & $0.18^{1}$ \\
\hline & The U.S. $\delta_{1}$ & & 0.16 & 0.14 & $X$ \\
\hline & China & & $4.52 .5-5.0$ & $4.04 .0-6.0$ & -0.11 \\
\hline MR Total & The U.S. & 14 & $3.02 .0-6.0$ & $4.53 .0-6.0$ & -0.11 \\
\hline
\end{tabular}

Notes: The $\delta$ effect size is considered to be (i) negligible if $|\delta|<0.147$, (ii) small if $0.147 \leq|\delta|<0.33$, (iii) medium if $0.33 \leq|\delta|<0.474$, and (iv) large if $|\delta| \geq 0.474 .{ }^{1}$ The $|\ln \theta|$ effect size thresholds are considered to be 0.51 (small), 1.24 (medium), and 1.90 (large).

In LEED-CIv4 (Table 8), in the Chinese projects, almost all of the MR credits had low performance in both the Silver and Gold projects, with the exception of MRc6 (Construction and Demolition Waste Management), which had high performance in both the Silver and Gold certifications, and MRc1 (Long-Term Commitment), which had medium performance in the Gold certification only. In the U.S. projects (Table 8), a large number of the MR credits also had low performance in both the Silver and Gold projects, with the exception of MRc1 and MRc6, which had high performance in both the Silver 
and Gold projects. Nevertheless, this resulted in higher U.S. Silver- and Gold-related MR category performance compared to the Chinese Silver and Gold projects.

It is interesting that MRc3, MRc4, and MRc5, in their current formulation with regard to the requirement of life cycle assessment (LCA) material declarations, were first introduced in LEEDv4 and, as was mentioned earlier, these credits were performed to a similarly low standard in both the Chinese and U.S. projects. Thereby, such LCA-based reformulation of these MR credits did not receive positive attention in either country. Other interesting results were revealed for MRc6 (Construction and Demolition Waste Management), in which China performed to a similarly high standard as the U.S., despite worse construction waste minimization laws/regulations in China compared to the U.S., as was discussed by Chi et al. [39].

Low performance of the MR category is also a well-known phenomenon in other countries. LEED-CIv3 Gold projects certified in Turkey, Spain, and Italy had the following low performances: $2.0 \pm 2.0,3.0 \pm 5.0,3.0 \pm 2.5$ achieved points, respectively [15]. LEED-CIv3 Silver and Gold projects certified in 14 U.S. states (CA, CO, FL, GA, IL, MD, MA, NJ, NY, NC, OH, PA, TX, and WA) also confirmed low Silver MR achievements, with the lowest (3.0 \pm 3.0 points) achieved in $\mathrm{CO}$ and the highest $(6.0 \pm 2.0$ points) achieved in PA [21].

Table 8. LEED-CIv4 Materials and Resources (MR) credits category: The median and 25th-75th centiles and Cliff's effect size $\left(\delta_{1}\right)$ of the difference between the achieved and the possible points, and $\left(\delta_{2}\right)$ or $\ln \theta$ of the difference between Silver and Gold projects in China and the U.S.

\begin{tabular}{|c|c|c|c|c|c|}
\hline \multirow{2}{*}{ Credit/Category } & \multirow{2}{*}{ Country/ $\delta_{1}$} & \multirow{2}{*}{$\begin{array}{l}\text { Possible } \\
\text { Points }\end{array}$} & \multicolumn{2}{|c|}{ Achieved Points } & \multirow{2}{*}{$\delta_{2} / \ln \theta$} \\
\hline & & & Silver & Gold & \\
\hline \multirow{4}{*}{$\begin{array}{l}\text { MRc1 Long-Term } \\
\text { Commitment }\end{array}$} & \multirow{2}{*}{ China $\delta_{1}$} & \multirow{4}{*}{1} & $0.00 .0-0.5$ & $0.00 .0-1.0$ & $-0.58^{1}$ \\
\hline & & & 0.31 & 0.45 & X \\
\hline & \multirow{2}{*}{ The U.S. $\delta_{1}$} & & $1.01 .0-1.0$ & $1.01 .0-1.0$ & $0.22^{1}$ \\
\hline & & & 0.84 & 0.81 & $X$ \\
\hline \multirow{4}{*}{$\begin{array}{l}\text { MRc2 Interior Life } \\
\text { Cycle Impact } \\
\text { Reduction }\end{array}$} & \multirow{2}{*}{ China $\delta_{1}$} & \multirow{4}{*}{4} & $0.00 .0-2.0$ & $0.00 .0-2.0$ & -0.04 \\
\hline & & & 0.00 & 0.00 & X \\
\hline & \multirow{2}{*}{ The U.S. $\delta_{1}$} & & $0.00 .0-1.0$ & $1.00 .0-1.0$ & -0.17 \\
\hline & & & 0.00 & 0.00 & \\
\hline MRc3 BPD and & \multirow{2}{*}{ China $\delta_{1}$} & \multirow{4}{*}{2} & $0.00 .0-0.0$ & $0.00 .0-0.0$ & -0.08 \\
\hline O-Environmental & & & 0.00 & 0.00 & X \\
\hline Product & \multirow{2}{*}{ The U.S. $\delta_{1}$} & & $1.00 .0-1.0$ & $1.00 .0-1.0$ & 0.06 \\
\hline Declarations & & & 0.00 & 0.00 & $X$ \\
\hline & \multirow{2}{*}{ China $\delta_{1}$} & \multirow{4}{*}{2} & $0.00 .0-0.0$ & $0.00 .0-0.0$ & -0.01 \\
\hline MRc4 BPD and & & & 0.00 & 0.00 & $x$ \\
\hline O-Sourcing of & \multirow{2}{*}{ The U.S. $\delta_{1}$} & & $0.00 .0-1.0$ & $0.00 .0-1.0$ & -0.01 \\
\hline Kaw Materials & & & 0.03 & 0.03 & $X$ \\
\hline \multirow{4}{*}{$\begin{array}{l}\text { MRc5 BPD and } \\
\text { O-Material } \\
\text { Ingredients }\end{array}$} & \multirow{2}{*}{ China $\delta_{1}$} & \multirow{4}{*}{2} & $0.00 .0-0.0$ & $0.00 .0-0.0$ & 0.01 \\
\hline & & & 0.00 & 0.00 & $x$ \\
\hline & \multirow{2}{*}{ The U.S. $\delta_{1}$} & & $1.00 .0-1.0$ & $1.00 .0-1.0$ & 0.04 \\
\hline & & & 0.08 & 0.00 & $X$ \\
\hline \multirow{4}{*}{$\begin{array}{l}\text { MRc6 Construction } \\
\text { and Demolition } \\
\text { Waste Management }\end{array}$} & \multirow{2}{*}{ China $\delta_{1}$} & \multirow{4}{*}{2} & $2.02 .0-2.0$ & $2.02 .0-2.0$ & -0.06 \\
\hline & & & 0.94 & 0.94 & X \\
\hline & \multirow{2}{*}{ The U.S. $\delta_{1}$} & & $2.01 .0-2.0$ & $2.01 .0-2.0$ & -0.05 \\
\hline & & & 0.68 & 0.72 & $X$ \\
\hline \multirow{2}{*}{ MR Total } & China & & $3.02 .0-4.0$ & $3.03 .0-5.0$ & -0.15 \\
\hline & The U.S. & 13 & $5.04 .0-6.0$ & $5.04 .0-6.5$ & -0.07 \\
\hline
\end{tabular}

Notes: BPD and O: BPD and O-Building Product Disclosure and Optimization. The $\delta$ effect size is considered to be (i) negligible if $|\delta|<0.147$, (ii) small if $0.147 \leq|\delta|<0.33$, (iii) medium if $0.33 \leq|\delta|<0.474$, and (iv) large if $|\delta| \geq 0.474$.

${ }^{1}$ The $|\ln \theta|$ effect size thresholds are considered to be 0.51 (small), 1.24 (medium), and 1.90 (large).

\subsection{Indoor Environmental Quality}

In LEED-CIv3 (Table 9), in the Chinese projects, seven credits (EQc2: Increased Ventilation; EQc3.1: Construction Indoor Air Quality (IAQ) Management Plan—During Construction; EQc3.2: Construction 
IAQ Management Plan-Before Occupancy; EQc4.1: Low-Emitting Materials-Adhesives and Sealants; EQc4.2: Low-Emitting Materials-Paints and Coatings; EQc7.1: Thermal Comfort-Design; EQc7.2: Thermal Comfort-Verification) had high performance in both the Silver and Gold projects, and two credits (EQc4.3: Low-Emitting Materials-Flooring Systems and EQc4.5: Low-Emitting Materials-Systems Furniture and Seating) had medium performance in the Gold certification only; all other EQ credits had low performance in both the Silver and Gold projects.

In the U.S. projects (Table 9), six credits (EQc3.1; EQc4.1; EQc4.2; EQc4.3: Low-Emitting Materials-Flooring Systems; EQc7.1; EQc7.2) had high performance in both the Silver and Gold certifications; two credits (EQc4.4: Low-Emitting Materials-Composite Wood and Agrifiber Products; EQc4.5) had medium and high performance in the Silver and Gold projects, respectively; EQc6.1 (Controllability of Systems-Lighting) had medium performance in both the Silver and Gold certifications; EQc1: Outdoor Air Delivery Monitoring and EQc2: Increased Ventilation had medium performance in the Gold certification only; and all other EQ credits had low performance in both the Silver and Gold projects. This resulted in similar Chinese and U.S. Silver and Gold-related EQ category performance.

Table 9. LEED-CI v3 Indoor Environmental Quality (QE) credits category: The median and 25th-75th centiles and Cliff's effect size $\left(\delta_{1}\right)$ of the difference between the achieved and the possible points, and $\left(\delta_{2}\right)$ or $\ln \theta$ of the difference between Silver and Gold projects in China and the U.S.

\begin{tabular}{|c|c|c|c|c|c|}
\hline \multirow{2}{*}{ Credit/Category } & \multirow{2}{*}{ Country $/ \delta_{1}$} & \multirow{2}{*}{$\begin{array}{l}\text { Possible } \\
\text { Points }\end{array}$} & \multicolumn{2}{|c|}{ Achieved Points } & \multirow{2}{*}{$\delta_{2} / \ln \theta$} \\
\hline & & & Silver & Gold & \\
\hline $\begin{array}{c}\text { EQc1 Outdoor Air } \\
\text { Delivery Monitoring }\end{array}$ & The U.S. $\delta_{1}$ & 1 & $\begin{array}{l}0.00 .0-0.0 \\
0.19 \\
0.00 .0-0.0 \\
0.22\end{array}$ & $\begin{array}{l}0.00 .0-1.0 \\
0.32 \\
0.00 .0-1.0 \\
\quad 0.44\end{array}$ & $\begin{array}{l}-0.69^{1} \\
X \\
-1.06^{1} \\
X\end{array}$ \\
\hline $\begin{array}{l}\text { EQc2 Increased } \\
\text { Ventilation }\end{array}$ & The U.S. $\delta_{1}$ & 1 & $\begin{array}{l}1.00 .5-1.0 \\
\mathbf{0 . 7 5} \\
0.00 .0-0.3 \\
0.24\end{array}$ & $\begin{array}{l}1.01 .0-1.0 \\
\quad \mathbf{0 . 7 6} \\
0.00 .0-1.0 \\
\quad \mathbf{0 . 4 4}\end{array}$ & $\begin{array}{c}-0.07^{1} \\
X \\
-0.91 \\
X\end{array}$ \\
\hline $\begin{array}{l}\text { EQc3.1 Construction } \\
\text { IAQ Management } \\
\text { Plan-During } \\
\text { Construction }\end{array}$ & The U.S. $\delta_{1}$ & 1 & $\begin{array}{c}1.01 .0-1.0 \\
\mathbf{0 . 8 7} \\
1.01 .0-1.0 \\
\mathbf{0 . 8 9}\end{array}$ & $\begin{array}{c}1.01 .0-1.0 \\
\mathbf{0 . 8 7} \\
1.01 .0-1.0 \\
\mathbf{0 . 8 9}\end{array}$ & $\begin{array}{c}0.06^{1} \\
X \\
0.03^{1} \\
X\end{array}$ \\
\hline $\begin{array}{l}\text { EQc3.2 Construction } \\
\text { IAQ Management } \\
\text { Plan-Before Occupancy }\end{array}$ & The U.S. $\delta_{1}$ & 1 & $\begin{array}{l}0.50 .0-1.0 \\
\quad \mathbf{0 . 5 0} \\
0.00 .0-0.0 \\
0.19\end{array}$ & $\begin{array}{l}1.00 .0-1.0 \\
\mathbf{0 . 5 2} \\
0.00 .0-0.5 \\
0.25\end{array}$ & $\begin{array}{c}-0.43^{1} \\
X \\
-0.36^{1} \\
X\end{array}$ \\
\hline $\begin{array}{l}\text { EQc4.1 Low-Emitting } \\
\text { Materials-Adhesives } \\
\text { and Sealants }\end{array}$ & The U.S. $\delta_{1}$ & 1 & $\begin{array}{c}1.01 .0-1.0 \\
\mathbf{0 . 8 1} \\
1.01 .0-1.0 \\
\mathbf{0 . 8 6}\end{array}$ & $\begin{array}{c}1.00 .0-1.0 \\
\mathbf{0 . 7 1} \\
1.01 .0-1.0 \\
\quad \mathbf{0 . 8 1}\end{array}$ & $\begin{array}{c}0.57^{1} \\
X \\
0.43^{1} \\
X\end{array}$ \\
\hline $\begin{array}{c}\text { EQc4.2 Low-Emitting } \\
\text { Materials-Paints and } \\
\text { Coatings }\end{array}$ & The U.S. $\delta_{1}$ & 1 & $\begin{array}{c}1.01 .0-1.0 \\
\mathbf{0 . 9 4} \\
1.01 .0-1.0 \\
\mathbf{0 . 9 5}\end{array}$ & $\begin{array}{c}1.01 .0-1.0 \\
\mathbf{0 . 9 5} \\
1.01 .0-1.0 \\
\mathbf{0 . 9 4}\end{array}$ & $\begin{array}{c}-0.18^{1} \\
X \\
0.03^{1} \\
X\end{array}$ \\
\hline $\begin{array}{c}\text { EQc4.3 Low-Emitting } \\
\text { Materials-Flooring } \\
\text { Systems }\end{array}$ & The U.S. $\delta_{1}$ & 1 & $\begin{array}{l}0.00 .0-0.0 \\
0.19 \\
1.00 .7-1.0 \\
\mathbf{0 . 7 6}\end{array}$ & $\begin{array}{c}0.00 .0-1.0 \\
\quad \mathbf{0 . 3 7} \\
1.01 .0-1.0 \\
\mathbf{0 . 8 9}\end{array}$ & $\begin{array}{l}-0.93^{1} \\
X \\
-0.94^{1} \\
X\end{array}$ \\
\hline $\begin{array}{c}\text { EQc4.4 Low-Emitting } \\
\text { Materials-Composite } \\
\text { Wood and Agrifiber } \\
\text { Products }\end{array}$ & The U.S. $\delta_{1}$ & 1 & $\begin{array}{l}0.00 .0-0.0 \\
0.00 \\
0.00 .0-1.0 \\
\quad 0.41\end{array}$ & $\begin{array}{l}0.00 .0-0.0 \\
0.05 \\
1.00 .0-1.0 \\
\quad 0.72\end{array}$ & $\begin{array}{l}-0.04^{1} \\
X \\
-1.34^{1} \\
X\end{array}$ \\
\hline $\begin{array}{l}\text { EQc4.5 Low-Emitting } \\
\text { Materials-Systems } \\
\text { Furniture and Seating }\end{array}$ & The U.S. $\delta_{1}$ & 1 & $\begin{array}{c}0.00 .0-1.0 \\
0.31 \\
0.00 .0-1.0 \\
0.46\end{array}$ & $\begin{array}{c}0.00 .0-1.0 \\
\mathbf{0 . 3 4} \\
1.00 .0-1.0 \\
\mathbf{0 . 5 1}\end{array}$ & $\begin{array}{c}-0.13^{1} \\
X \\
-0.54^{1} \\
X\end{array}$ \\
\hline
\end{tabular}


Table 9. Cont

\begin{tabular}{|c|c|c|c|c|c|}
\hline \multirow{2}{*}{ Credit/Category } & \multirow{2}{*}{ Country/ $\delta_{1}$} & \multirow{2}{*}{$\begin{array}{l}\text { Possible } \\
\text { Points }\end{array}$} & \multicolumn{2}{|c|}{ Achieved Points } & \multirow{2}{*}{$\delta_{2} / \ln \theta$} \\
\hline & & & Silver & Gold & \\
\hline \multirow{4}{*}{$\begin{array}{c}\text { EQc5 Indoor Chemical } \\
\text { and Pollutant Source } \\
\text { Control }\end{array}$} & \multirow{2}{*}{ China $\delta_{1}$} & \multirow{4}{*}{1} & $0.00 .0-0.0$ & $0.00 .0-0.0$ & $-0.78^{1}$ \\
\hline & & & 0.12 & 0.24 & X \\
\hline & \multirow{2}{*}{ The U.S. $\delta_{1}$} & & $0.00 .0-1.0$ & $0.00 .0-1.0$ & $-0.16^{1}$ \\
\hline & & & 0.32 & 0.32 & $x$ \\
\hline \multirow{4}{*}{$\begin{array}{l}\text { EQc6.1 Controllability of } \\
\text { Systems-Lighting }\end{array}$} & \multirow{2}{*}{ China $\delta_{1}$} & \multirow{4}{*}{1} & $0.00 .0-0.0$ & $0.00 .0-0.0$ & $-1.39^{1}$ \\
\hline & & & 0.06 & 0.21 & X \\
\hline & \multirow{2}{*}{ The U.S. $\delta_{1}$} & & $0.00 .0-1.0$ & $0.00 .0-1.0$ & $0.07^{1}$ \\
\hline & & & 0.41 & 0.39 & $X$ \\
\hline \multirow{4}{*}{$\begin{array}{l}\text { EQc6.2 Controllability of } \\
\text { Systems-Thermal } \\
\text { Comfort }\end{array}$} & \multirow{2}{*}{ China $\delta_{1}$} & \multirow{4}{*}{1} & $0.00 .0-0.0$ & $0.00 .0-0.0$ & $0.18^{1}$ \\
\hline & & & 0.06 & 0.05 & X \\
\hline & \multirow{2}{*}{ The U.S. $\delta_{1}$} & & $0.00 .0-0.0$ & $0.00 .0-0.0$ & $-1.04^{1}$ \\
\hline & & & 0.05 & 0.04 & X \\
\hline \multirow{4}{*}{$\begin{array}{l}\text { EQc7.1 Thermal } \\
\text { Comfort-Design }\end{array}$} & \multirow{2}{*}{ China $\delta_{1}$} & \multirow{4}{*}{1} & $1.01 .0-1.0$ & $1.01 .0-1.0$ & $0.07^{1}$ \\
\hline & & & 1.00 & 0.92 & $X$ \\
\hline & \multirow{2}{*}{ The U.S. $\delta_{1}$} & & $1.01 .0-1.0$ & $1.01 .0-1.0$ & $0.03^{1}$ \\
\hline & & & 0.92 & 0.92 & $x$ \\
\hline \multirow{4}{*}{$\begin{array}{c}\text { EQc7.2 Thermal } \\
\text { Comfort-Verification }\end{array}$} & \multirow{2}{*}{ China $\delta_{1}$} & \multirow{4}{*}{1} & $1.01 .0-1.0$ & $1.01 .0-1.0$ & $0.06^{1}$ \\
\hline & & & 0.87 & 0.87 & X \\
\hline & \multirow{2}{*}{ The U.S. $\delta_{1}$} & & $1.00 .0-1.0$ & $1.00 .0-1.0$ & $0.42^{1}$ \\
\hline & & & 0.73 & 0.68 & $X$ \\
\hline \multirow{4}{*}{$\begin{array}{l}\text { EQc8.1 Daylight and } \\
\text { Views-Daylight }\end{array}$} & \multirow{2}{*}{ China $\delta_{1}$} & \multirow{4}{*}{2} & $0.00 .0-1.0$ & $0.00 .0-1.0$ & 0.01 \\
\hline & & & 0.19 & 0.11 & $X$ \\
\hline & \multirow{2}{*}{ The U.S. $\delta_{1}$} & & $0.00 .0-0.0$ & $0.00 .0-0.0$ & 0.00 \\
\hline & & & 0.05 & 0.00 & X \\
\hline \multirow{4}{*}{$\begin{array}{l}\text { EQc8.2 Daylight and } \\
\text { Views-Views }\end{array}$} & China $\delta_{1}$ & & $0.00 .0-0.5$ & $0.00 .0-1.0$ & $-0.44^{1}$ \\
\hline & Minta $0_{1}$ & & 0.25 & 0.32 & $X$ \\
\hline & The U.S. $\delta_{1}$ & 1 & $0.00 .0-0.0$ & $0.00 .0-1.0$ & $-0.95^{1}$ \\
\hline & 1, U.s. 1 & & 0.16 & 0.32 & X \\
\hline & China & & $7.06 .0-8.0$ & $8.57 .0-10.0$ & -0.22 \\
\hline EQ Total & The U.S. & 17 & $8.06 .0-9.3$ & $9.08 .0-10.0$ & -0.31 \\
\hline
\end{tabular}

Notes: IAQ-Indoor Air Quality. The $\delta$ effect size is considered to be (i) negligible if $|\delta|<0.147$, (ii) small if $0.147 \leq|\delta|$ $<0.33$, (iii) medium if $0.33 \leq|\delta|<0.474$, and (iv) large if $|\delta| \geq 0.474 .{ }^{1}$ The $|\ln \theta|$ effect size thresholds are considered to be 0.51 (small), 1.24 (medium), and 1.90 (large).

In LEED-CIv4 (Table 10), in the Chinese projects, three credits (EQc1: Enhanced Indoor Air Quality Strategies; EQc3: Construction Indoor Air Quality Management Plan; EQc8: Quality Views) had high performance in both the Silver and Gold certifications; EQc5 (Thermal Comfort) had low and medium performance in the Silver and Gold certifications, respectively; EQc5: Thermal Comfort had medium performance in the Gold certification only; and all other credits had low performance in both the Silver and Gold certifications.

In the U.S. projects (Table 10), only EQc3 had high performance in both the Silver and Gold certifications, while two credits (EQc1: Enhanced Indoor Air Quality Strategies; EQc8: Quality Views) had medium and high performance in the Silver and Gold certifications, respectively; all other credits had low performance in both the Silver and Gold certifications. Because California was the state with the largest number of analyzed projects, these high achievements in EQc1 and EQc3 were expected because of the strict requirements related to interior contamination contained in California's Code of Regulations, Title 24, Section 5.504 Pollutant Control and Section 5.504.1 Temporary ventilation, respectively [31].

This resulted in similar Chinese and U.S. Silver and Gold-related EQ category performance. However, in China, the Gold EQ performance was much better than the Silver EQ performance compared to the U.S., who had similar Silver and Gold EQ performances. 
Table 10. LEED-CIv4 Indoor Environmental Quality (QE) credits category: The median and 25th-75th centiles and Cliff's effect size $\left(\delta_{1}\right)$ of the difference between the achieved and the possible points, and $\left(\delta_{2}\right)$ or $\ln \theta$ of the difference between Silver and Gold projects in China and the U.S.

\begin{tabular}{|c|c|c|c|c|c|}
\hline \multirow{2}{*}{ Credit/Category } & \multirow{2}{*}{ Country/ $\delta_{1}$} & \multirow{2}{*}{$\begin{array}{l}\text { Possible } \\
\text { Points }\end{array}$} & \multicolumn{2}{|c|}{ Achieved Points } & \multirow{2}{*}{$\delta_{2} / \ln \theta$} \\
\hline & & & Silver & Gold & \\
\hline \multirow{4}{*}{$\begin{array}{l}\text { EQc1 Enhanced Indoor } \\
\text { Air Quality Strategies }\end{array}$} & \multirow{2}{*}{ China $\delta_{1}$} & \multirow{4}{*}{2} & $1.01 .0-2.0$ & $2.01 .0-2.0$ & -0.40 \\
\hline & & & 0.51 & 0.71 & X \\
\hline & \multirow{2}{*}{ The U.S. $\delta_{1}$} & & $1.01 .0-2.0$ & $1.51 .0-2.0$ & 0.01 \\
\hline & & & 0.35 & 0.50 & X \\
\hline \multirow{4}{*}{$\begin{array}{c}\text { EQc2 Low-Emitting } \\
\text { Materials }\end{array}$} & \multirow{2}{*}{ China $\delta_{1}$} & \multirow{4}{*}{3} & $0.00 .0-2.0$ & $1.00 .0-2.0$ & -0.05 \\
\hline & & & 0.16 & 0.21 & $X$ \\
\hline & \multirow{2}{*}{ The U.S. $\delta_{1}$} & & $1.01 .0-3.0$ & $1.00 .0-3.0$ & 0.16 \\
\hline & & & 0.30 & 0.28 & $X$ \\
\hline \multirow{4}{*}{$\begin{array}{l}\text { EQc3 Construction } \\
\text { Indoor Air Quality } \\
\text { Management Plan }\end{array}$} & \multirow{2}{*}{ China $\delta_{1}$} & \multirow{4}{*}{1} & $1.01 .0-1.0$ & $1.01 .0-1.0$ & 0.00 \\
\hline & & & 1.00 & 0.97 & X \\
\hline & \multirow{2}{*}{ The U.S. $\delta_{1}$} & & $1.01 .0-1.0$ & $1.01 .0-1.0$ & $0.08^{1}$ \\
\hline & & & 1.00 & 0.92 & X \\
\hline \multirow{4}{*}{$\begin{array}{c}\text { EQc4 Indoor Air Quality } \\
\text { Assessment }\end{array}$} & \multirow{2}{*}{ China $\delta_{1}$} & \multirow{4}{*}{2} & $1.00 .0-1.0$ & $1.01 .0-2.0$ & $-0.28^{1}$ \\
\hline & & & 0.06 & 0.26 & $\mathrm{X}$ \\
\hline & \multirow{2}{*}{ The U.S. $\delta_{1}$} & & $0.00 .0-1.0$ & $0.00 .0-2.0$ & -0.26 \\
\hline & & & 0.11 & 0.32 & $x$ \\
\hline \multirow{4}{*}{ EQc5 Thermal Comfort } & \multirow{2}{*}{ China $\delta_{1}$} & \multirow{4}{*}{1} & $0.00 .0-0.5$ & $0.00 .0-1.0$ & $-0.89^{1}$ \\
\hline & & & 0.25 & 0.45 & X \\
\hline & \multirow{2}{*}{ The U.S. $\delta_{1}$} & & $0.00 .0-0.0$ & $0.00 .0-0.0$ & $-0.86^{1}$ \\
\hline & & & 0.11 & 0.22 & $x$ \\
\hline \multirow{4}{*}{ EQc6 Interior Lighting } & China $\delta_{1}$ & & $0.00 .0-1.0$ & $1.00 .0-1.0$ & -0.37 \\
\hline & Cillia $0_{1}$ & 2 & 0.06 & 0.21 & X \\
\hline & & 2 & 1.0 0.0-1.0 & $1.00 .0-1.0$ & -0.10 \\
\hline & The U.S. $\delta_{1}$ & & 0.11 & 0.22 & X \\
\hline & China $\delta_{1}$ & & $0.00 .0-0.0$ & $0.00 .0-2.0$ & -0.25 \\
\hline EOc7 Daylight & China $\delta_{1}$ & & 0.00 & 0.13 & $x$ \\
\hline EQc/ Dayngnt & & 3 & $0.00 .0-0.0$ & $0.00 .0-0.0$ & -0.08 \\
\hline & The U.S. $\delta_{1}$ & & 0.05 & 0.06 & $x$ \\
\hline & & & $1.00 .0-1.0$ & $1.00 .0-1.0$ & $0.15^{1}$ \\
\hline FOc8 Ouality Views & China $\delta_{1}$ & & 0.56 & 0.53 & X \\
\hline EQc8 Quality Views & The UIS $\delta_{1}$ & 1 & $0.00 .0-1.0$ & $1.00 .0-1.0$ & $-0.84^{1}$ \\
\hline & Ine U.S. $\delta_{1}$ & & 0.35 & 0.52 & X \\
\hline & China $\delta_{1}$ & & $0.00 .0-0.0$ & $0.00 .0-0.0$ & 0.00 \\
\hline EQc9 Acoustic & & ? & 0.00 & 0.00 & $X$ \\
\hline Performance & The US $\delta_{1}$ & 2 & $0.00 .0-0.0$ & $0.00 .0-0.0$ & 0.00 \\
\hline & The U.S. $o_{1}$ & & 0.05 & 0.06 & $x$ \\
\hline & China & & $5.04 .0-7.0$ & $7.06 .0-8.0$ & -0.52 \\
\hline EQ Total & The U.S. & 17 & $5.04 .0-6.0$ & $6.54 .0-8.0$ & -0.17 \\
\hline
\end{tabular}

Notes: The $\delta$ effect size is considered to be (i) negligible if $|\delta|<0.147$, (ii) small if $0.147 \leq|\delta|<0.33$, (iii) medium if $0.33 \leq|\delta|<0.474$, and (iv) large if $|\delta| \geq 0.474 .{ }^{1}$ The $\ln \theta$ effect size thresholds are considered to be 0.51 (small), 1.24 (medium), and 1.90 (large).

It should be pointed out that both the Chinese and U.S. projects in the LEED-CIv3 certification succeeded in six/seven high performance credits, respectively (Table 9), whereas, in the LEED-CIv4 certification, only one to three credits were performed to a high standard in these countries (Table 10). For the EQ category, the main difference between LEED-CIv3 and LEED-CIv4 is the number of available credits in these versions. LEED-CIv3 has 16 EQ credits (Table 9), whereas LEED-CIv4 has only nine credits (Table 10). This is due to the grouping of some separate credits of LEED-CIv3 into representative unique credits in LEED-CIv4. For example, the five separate credits of low-emitting materials of LEED-CIv3 (i.e., EQc4.1-EQc4.5, each with one awarding point) were grouped into one credit (EQc2: Low-Emitting Materials) in LEED-CIv4 with three awarding points. It can be suggested 
that a large number of separately presented credits can allow a much better adaptation of the EQ credits to country-specific environmental concerns.

\section{Conclusions}

LEED, as a generally accepted international building rating system, has tried to take into account the environmental priorities of countries other than the US. In this regard, a flexible weighting system of LEED points toward adaptation to the environmental problems of different countries is viewed as a necessary component in future LEED versions. The main contribution of this study is to provide feedback from the projects certified under LEED-CI v3 and v4 in two completely different countries, China and the U.S. Based on country-specific data, as in this study, LEED developers will be able to build a flexible weighting system adapted to different countries. Moreover, this study presents detailed knowledge of the awarded credits to potential owners or occupants, to allow them to be better informed about the benefits of Silver and Gold LEED buildings in these two countries.

The main findings are:

- From Silver to Gold, in the Chinese projects, the categories' performance increased in SS, EA, and EQ with large effect size, in WE with medium effect size, and in LT with small effect size, whereas, in the U.S. projects, the categories' performance increased in EA with large effect size, in WE with medium effect size, and in SS, LT, and EQ with small effect size.

- From LEED-CI v3 to v4, in the Chinese projects, only WE performance increased, whereas, in the U.S. projects, only EA performance increased; in both countries, the EQ category's performance decreased, and the SS/LT category's performance remained almost the same.

It can be concluded that in both LEED-CI v3 and v4, the Chinese and U.S. projects employed different strategies for the categories' performances: China performed better than the U.S. in the SS/LT and WE categories, whereas the U.S. performed better than China in the EA and MR categories. Thus, China's owners of Gold-certified projects will receive more sustainable buildings with improvements in almost all of the LEED-CI categories compared to the owners of Silver-certified projects, whereas the U.S. owners of Gold-certified projects will receive buildings with only energy and water use improvements compared to the owners of Silver-certified projects. Moreover, China's owners of LEED-CIv4-certified projects will receive buildings with only water use improvements compared to the owners of LEED-CIv3-certified projects, whereas U.S. owners of LEED-CIv4-certified projects will receive buildings with only energy use improvements compared to the owners of LEED-CIv3-certified projects.

This study has a limitation, namely a relatively small sample size because, to date, a relatively small number of projects are certified by the current version of LEED-CI v4. As a result, the quantity of the selected LEED v3 projects was also relatively small because of the data collection methodology. This means that a relatively small sample size of the projects certified under the current LEED-CIv4 restricted the sample size of the projects certified under the previous LEED-CIv3. In this way, the total sample size was limited.

Funding: This research received no external funding.

Conflicts of Interest: The author declares that there is no conflict of interest.

\section{References}

1. Ade, R.; Rehm, M. The unwritten history of green building rating tools: A personal view from some of the 'founding fathers'. Build. Res. Inform. 2020, 48, 1-17. [CrossRef]

2. ISO15392:2008 Building Construction—Sustainability in Building Construction—General Principles; International Organization for Standardization: Geneva, Switzerland, 2008.

3. Castellano, J.; Ribera, A.; Ciurana, J. Integrated system approach to evaluate social, environmental and economics impacts of buildings for users of housings. Energy Build. 2016, 123, 106-118. [CrossRef]

4. Illankoon, I.C.; Tam, V.W.; Le, K.N. Environmental, economic, and social parameters in international green building rating tools. J. Prof. Issues Eng. Educ. Pract. 2017, 143, 05016010. [CrossRef] 
5. Wu, P.; Song, Y.Z.; Shou, W.C.; Chi, H.L.; Chong, H.Y.; Sutrisna, M. A comprehensive analysis of the credits obtained by LEED 2009 certified green buildings. Renew. Sustain. Energy Rev. 2017, 68 Pt 1, 370-379. [CrossRef]

6. Dall'O, G.; Bruni, E.; Panza, A. Improvement of the Sustainability of Existing School Buildings According to the Leadership in Energy and Environmental Design (LEED) ${ }^{\circledR}$ Protocol: A Case Study in Italy. Energies 2013, 6, 6487-6507. [CrossRef]

7. Sun, X.; Gou, Z.; Lu, Y.; Tao, Y. Strengths and Weaknesses of Existing Building Green Retrofits: Case Study of a LEED EBOM Gold Project. Energies 2018, 11, 1936. [CrossRef]

8. Mazzola, E.; Mora, T.D.; Peron, F.; Romagnoni, P. An Integrated Energy and Environmental Audit Process for Historic Buildings. Energies 2019, 12, 3940. [CrossRef]

9. Suzer, O. A comparative review of environmental concern prioritization: LEED vs other major certification systems. J. Environ. Manag. 2015, 154, 266-283. [CrossRef]

10. LEED 2009 for New Construction and Major Renovations Rating System USGBC Member Approved November 2008-Campbell. Available online: https://www.ci.campbell.ca.us/DocumentCenter/View/3103/ Commercial-Construction-Guidelines?bidId= (accessed on 10 January 2020).

11. Faulconbridge, J. Mobilising sustainable building assessment models: Agents, strategies and local effects. Area 2015, 47, 116-123. [CrossRef]

12. LEED-CIv4. LEED v4 for Interior Design and Construction. 2014. Available online: File://C:/Users/user/ Documents/Journal\%20Papers/LEED-CIv4/LEEDv4forInteriorDesignandConstructionBallotVersion.pdf (accessed on 10 January 2020).

13. Wu, P.; Song, Y.; Wang, J.; Wang, X.; Zhao, X.; He, Q. Regional variations of credits obtained by LEED 2009 Certified green buildings-A country level analysis. Sustainability 2018, 10, 20. [CrossRef]

14. Pushkar, S. A comparative analysis of Gold Leadership in Energy and Environmental Design for New Construction 2009 Certified projects in Finland, Sweden, Turkey, and Spain. Appl. Sci. 2018, 8, 1496. [CrossRef]

15. Pushkar, S. The effect of regional priority points on the performance of LEED 2009 Certified Buildings in Turkey, Spain, and Italy. Sustainability 2018, 10, 3364. [CrossRef]

16. Pham, D.H.; Kim, B.; Lee, J.; Ahn, A.C.; Ahn, Y. A comprehensive analysis: Sustainable trends and awarded LEED 2009 credits in Vietnam. Sustainability 2020, 12, 852. [CrossRef]

17. Cracknell, T.M.; Abu-Hijleh, B. Measuring LEED-NC applicability in design for hospitality. Front. Arch. Res 2015, 4, 308-317. [CrossRef]

18. Pushkar, S. Sacrificial pseudoreplication in LEED Cross-Certification Strategy Assessment: Sampling Structures. Sustainability 2018, 10, 1353. [CrossRef]

19. Pushkar, S.; Verbitsky, O. LEED-NCv3 silver and gold certified projects in the US: An observational study. J. Green Build. 2018, 13, 67-83. [CrossRef]

20. Pushkar, S.; Verbitsky, O. LEED-NC 2009 Silver To Gold Certified Projects in the US in 2012-2017: An Appropriate Statistical Analysis. J. Green Build. 2019, 14, 83-107. [CrossRef]

21. Pushkar, S.; Verbitsky, O. Silver and Gold LEED Commercial Interiors: Certified Projects. J. Green Build. 2019, 14, 95-113. [CrossRef]

22. USGBC Projects Site. Available online: https://www.usgbc.org/projects (accessed on 10 January 2020).

23. Cliff, N. Dominance statistics: Ordinal analyses to answer ordinal questions. Psychol. Bull. 1993, 114, 494-509. [CrossRef]

24. Romano, J.; Corragio, J.; Skowronek, J. Appropriate statistics for ordinal level data: Should we really be using t-test and Cohen's d for evaluating group differences on the NSSE and other surveys? In Proceedings of the Annual Meeting of the Florida Association of Institutional Research, Cocoa Beach, FL, USA, 1-3 February 2006; Florida Association for Institutional Research: Cocoa Beach, FL, USA, 2006; pp. 1-33.

25. Haddock, C.K.; Rindskopf, D.; Shadish, W.R. Using odds ratios as effect sizes for meta-analysis of dichotomous data: A primer on methods and issues. Psychol. Methods 1998, 3, 339-353. [CrossRef]

26. Chen, H.; Cohen, P.; Chen, S. How Big is a Big Odds Ratio? How big is a big odds ratio? Interpreting the magnitudes of odds ratios in epidemiological studies. Commun. Stat.—Simul. Comput.® 2010, 39, 860-864. [CrossRef]

27. Durlak, J.A. How to select, calculate, and interpret effect sizes. J. Pediatr. Psychol. 2009, 34, 917-928. [CrossRef] [PubMed] 
28. Volker, M.A. Reporting effect size estimates in school psychology research. Psychol. Sch. 2006, 43, 653-672. [CrossRef]

29. Gu, X.; Li, Q.; Chand, S. Factors influencing residents' access to and use of country parks in Shanghai, China. Cities 2020, 97, 102501. [CrossRef]

30. Liang, H.; Zhang, Q. Assessing the public transport service to urban parks on the basis of spatial accessibility for citizens in the compact megacity of Shanghai, China. Urban Stud. 2018, 55, 1983-1999. [CrossRef]

31. California Green Building Standards Code 2016. Available online: https://up.codes/viewer/california/cagreen-code-2016 (accessed on 10 April 2020).

32. Zhao, X.; Liu, J.; Liu, Q.; Tillotson, M.R.; Guan, D.; Hubacek, K. Physical and virtual water transfers for regional water stress alleviation in China. Proc. Natl. Acad. Sci. USA 2015, 112, 1031-1035. [CrossRef]

33. Zhao, X.; Liu, J.; Yang, H.; Duarte, R.; Tillotson, M.R.; Hubacek, K. Burden shifting of water quantity and quality stress from megacity Shanghai. Water Resour. Res. 2016, 52, 6916-6927. [CrossRef]

34. Greer, F.; Chittick, J.; Jackson, E.; Mack, J.; Shortlidge, M.; Grubert, E. Energy and water efficiency in LEED: How well are LEED points linked to climate outcomes? Energy Build. 2019, 195, 161-167. [CrossRef]

35. Gurgun, A.P.; Arditi, D. Assessment of energy credits in LEED-Certified Buildings based on certification levels and project ownership. Buildings 2018, 8, 29. [CrossRef]

36. Adekanye, O.G.; Davis, A.; Azevedo, I.L. Federal policy, local policy, and green building certifications in the U.S. Energy Build. 2020, 209, 109700. [CrossRef]

37. Hast, A.; Alimohammadisagvand, B.; Syri, S. Consumer attitudes towards renewable energy in China-The case of Shanghai. Sustain. Cities Soc. 2015, 17, 69-79. [CrossRef]

38. Pushkar, S. LEED-CIv4 Commercial Interiors: United States (2014-2019). Sustainability 2020, 12, 69. [CrossRef]

39. Chi, B.; Lu, W.S.; Ye, M.; Bao, Z.K.; Zhang, X.L. Construction waste minimization in green building: A comparative analysis of LEED-NC 2009 certified projects in the US and China. J. Clean. Prod. 2020, 256, 120749. [CrossRef]

(C) 2020 by the author. Licensee MDPI, Basel, Switzerland. This article is an open access article distributed under the terms and conditions of the Creative Commons Attribution (CC BY) license (http://creativecommons.org/licenses/by/4.0/). 